\title{
Alcohol consumption and cigarette smoking pattern among brothel- based female sex workers in two local government areas in Lagos state, Nigeria
}

\author{
*Odukoya $\mathrm{OO}^{1}$, Sekoni $\mathrm{AO}^{1}$, Onajole $\mathrm{AT}^{1}$, Upadhyay RP²
}

1. Department of Community Health and Primary Care, College of Medicine, University of Lagos, Lagos State, Nigeria.

2. Department of Community Medicine, Vardhman Mahavir Medical College and Safdarjung Hospital, New Delhi, India

\begin{abstract}
Background: Alcohol and tobacco use are known risk factors for non communicable diseases especially among women. Brothel based female sex workers may be at increased risk of exposure to these two substances.

Objective: To assess the pattern of alcohol and tobacco use among female sex workers in two selected local government areas in Lagos state, Nigeria.

Methods: A cross-sectional descriptive study was carried out among 323 brothel-based female sex workers in 39 consenting brothels. Data was collected by trained interviewers using a pretested structured questionnaire.

Results: Majority (67.8\%) were current drinkers with $89.5 \%$ of these having their most recent drink less than a week ago. Most of them (89\%) consumed more than the reference limits for alcohol use among women. Up to $20.7 \%$ were current smokers with (92.5\%) having their most recent cigarette less than a week ago. More than a third (37.4\%) were heavy smokers while $19 \%$ were dual users. Current drinking was associated with current smoking. Smokers consumed significantly more units of alcohol than non-smokers.

Conclusion: The prevalence of harmful alcohol use and cigarette smoking are very high among this group of female sex workers. Programs that address the use of these substances should be made available for these women.

African Health Sciences 2013; 13(2): 490 - 497 http:/ / dx.doi.org/10.4314/ahs.v13i2.41
\end{abstract}

\section{Introduction}

Globally, tobacco use and the harmful consumption of alcohol (as defined by the World Health Organization) have been identified as two important shared risk factors for $80 \%$ of non-communicable diseases (NCD's). ${ }^{1.2}$ Tobacco use is the second leading cause of death while the harmful use of alcohol is the third leading cause of morbidity. ${ }^{3}$ In many cases, there is a synergism between tobacco and alcohol use. Studies in high income countries have found that people who smoke are much more likely to drink, and vice versa. ${ }^{4}$ Dependence on alcohol and tobacco may also be correlated; people who were dependent on alcohol were three times more likely than those in the general population to be smokers, and people who were dependent on tobacco were

\section{*Correspondence author:}

Oluwakemi Odukoya

Department of Community Health and Primary Care

College of Medicine, University of Lagos

Lagos State, Nigeria

Email: drolukemiodukoya@yahoo.com four times more likely than the general population to be dependent on alcohol. ${ }^{5}$

Alcohol and tobacco use may lead to major health risks when used alone or together. In addition to contributing to traumatic death and injury, alcohol use is associated with chronic liver disease, cancers, cardiovascular disease, acute alcohol poisoning and fetal alcohol syndrome. ${ }^{6}$ Tobacco use affects almost every organ in the human body. It is associated with lung disease, cancers, and cardiovascular disease ${ }^{7}$ among others. A growing body of evidence suggests that these substances might be especially dangerous when they are used together; when combined, alcohol and tobacco use dramatically increase the risk of certain cancers ${ }^{8}$ particularly those of the mouth and throat ${ }^{9-11}$. In fact, the combined risk may be greater than the risk associated with either substance when taken separately. ${ }^{12}$

Tobacco and alcohol use disproportionately affects the health of women. Tobacco use is a risk factor for osteoporosis, menstrual problems and some gynaecological cancers. ${ }^{13}$ Women absorb more alcohol and metabolize it more slowly when 
compared to men. This makes women more vulnerable to alcohol's long-term health effects. ${ }^{14}$ Women are also more likely than men to develop alcoholic hepatitis and to die from liver cirrhosis. ${ }^{15}$ In addition, smoking and drinking in pregnancy may pose special problems for the woman and her child such as miscarriages, low birth weight, birth defects, fetal alcohol syndrome (FAS) and Sudden Infant death Syndrome (SIDS). ${ }^{16,17}$

In 2004, the World Health Organization (WHO) Global Status on Alcohol Report stated that in Nigeria, the alcohol drinking rate was $34.9 \%$ in males and $23 \%$ in females. The rate of heavy and hazardous drinking among drinkers was however higher among women $(36.1 \%)$ than men $(27.8 \%) .{ }^{18}$ This may indicate that even though the proportion of women consuming alcohol may be lower than men; among the women who do consume alcohol, the proportion of harmful drinking may be higher than for men. On the other hand, the prevalence of tobacco use among Nigerian women as a whole is said to be very low. The 2008 NDHS reported rates of less than one percent among Nigerian women. ${ }^{19}$ The data on both smoking and alcohol use were however not stratified according to the womens' occupational profile particularly sex work.

As a hidden and lucrative industry, commercial sex is increasing globally ${ }^{20}$ and has social characteristics that tend to influence both drinking and smoking. ${ }^{21-23}$ Brothels may serve as outlets which promote the sale and use of alcohol and tobacco products. ${ }^{24,25}$ Female sex workers (FSW) who live and work in these brothels may be at increased risk of exposure to these substances. A study reported that tobacco use was the commonest substance used by female sex workers with $45.8 \%$ using tobacco products. ${ }^{26}$ Alcohol use has also been recognized as an important aspect of commercial sex and it is reported that FSW's who operate in alcohol-selling or alcohol-serving venues drink higher levels of alcohol. ${ }^{25}$ In Nigeria, many health programs carried out for FSW's focus primarily on risky sexual behavior and the prevention of sexually transmitted infections with the exclusion of known NCD risk factors like alcohol and tobacco which may be prevalent among these women. There is limited information on the pattern of alcohol and tobacco use among Nigerian FSW's.

This study aimed to assess the pattern of alcohol and tobacco use among female sex workers in Lagos with a view of generating data for the effective primary prevention of tobacco and alcohol related NCD's among this group of the women.

\section{Methods}

Lagos state is located in the south western part of Nigeria with the southern boundary framed by a 180-kilometer long Atlantic coastline, northern \& eastern boundaries by Ogun state while the Republic of Benin forms the western boundary. It is considered the commercial and economic capital of Nigeria with a population of 9,013,534 according to the 2006 national population census. The state is made up of twenty local government areas (LGA's). Two adjoining LGA's, one urban and the other rural (namely, Ojo and Badagry) were purposively selected for this study. This was because of their close proximity to the border with Republic of Benin which results in a high number of migrant population, traders, long distance drivers, youths and female sex workers. ${ }^{27}$ An army cantonment and an international trade fair complex are also located in this area.

A cross sectional descriptive study was carried out between March and April 2011 to assess the alcohol and cigarette smoking patterns among brothel-based FSW's in the two LGA's. Community mapping was carried out and all the brothels (41 in number) with resident female sex workers were identified. Advocacy visits were conducted to all the brothels and meetings were held with the manager and the chairlady (female sex workers representative). Thirty-nine brothels agreed to participate in the survey (Brothel response rate was 95.1\%). A list of all the female sex workers aged 18 years and above (383 in number) in the participating brothels was then prepared.

The sample size for the study was estimated using the formula for estimation of sample size for descriptive studies and considering the cluster design of the survey. Prevalence values for current smoking, current drinking and dual use were initially used to compute the sample size..$^{25,28,34}$ Of these, the prevalence that provided the highest sample size estimation was used for the study. Hence, a minimum sample size of 270 was calculated using a prevalence of current alcohol use of $33 \%$, confidence level of $95 \%$, alpha of 0.05 , precision of $5 \%$ and a total population of 383 FSW's in the two LGA's. Considering a non-response rate of $10 \%$, the final sample size was estimated to be 298; nevertheless all consenting and eligible FSW's were surveyed. Attempts were made to reach out to all the eligible female sex workers in each participating brothel for their consent to participate in the study. Out of the total 383 eligible female sex workers, 323 agreed to 
participate in the study. (FSW response rate was $84.3 \%)$

Data was collected by trained interviewers using a pretested structured questionnaire. The questionnaire elicited information on socio demographics, duration of sex work, age of initiation and the frequency and quantity of alcohol and cigarette use if any. To estimate the amount of alcohol consumed, respondents were asked to state the quantity and exact type of alcohol consumed within a 7 -day recall period. This was converted into standard units of alcohol using the standard formula for conversion of alcohol content into units. ${ }^{29}$ Ethical approval was obtained from the ethical board of the Lagos University Teaching Hospital.

Data was entered and analyzed using EpiInfo 3.5.1 and SPSS 16.0 (Chicago, IL, USA). Data analysis involved the use of frequency tables, student's T-test and chi-square tests as appropriate. $\mathrm{P}$ values of $<0.05$ were said to be statistically significant.

\section{Results}

All the respondents were female and aged between 18 and 48 years. The mean age was $28.1 \pm 6.8$ years. Most of them were single $(62.5 \%)$ and had primary education or less $(68.4 \%)$. About half of them $(49.2 \%)$ had been engaged in sex work for over a year as indicate in table 1.

Table 1: The socio-demographic characteristics of the respondents $(n=323)$

\begin{tabular}{lc}
\hline Socio-demographic variable & Freq. (\%) \\
\hline Age group (years) & $108(33.4)$ \\
$15-24$ & $159(49.2)$ \\
$25-34$ & $48(14.9)$ \\
$35-44$ & $8(2.5)$ \\
45 and above & \\
Marital status & $16(5.0)$ \\
Married & $92(28.5)$ \\
Separated/Divorced & $202(62.5)$ \\
Single & $13(4.0)$ \\
Widowed & \\
Highest level of education & $25(7.7)$ \\
No formal education & $196(60.7)$ \\
Primary & $102(31.6)$ \\
Secondary education and above & \\
Religion & $307(95.1)$ \\
Christianity & $16(4.9)$ \\
Islam & \\
Duration of sex work & $80(24.8)$ \\
Less than six months & $84(26.0)$ \\
Six-twelve months & $159(49.2)$ \\
Above one year & \\
\hline 492 &
\end{tabular}

Majority $(67.8 \%)$ of the respondents currently consumed alcohol with $89.5 \%$ of these having their most recent drink less than a week prior to the study. The number of units consumed in the last week ranged from 0-416 standard alcohol units with a median of 69.3 units (IQR=23.1-138.6 units). Most of them $(89 \%)$ consumed more than the reference limits for alcohol use among women (14 units per week). ${ }^{30}$ Almost a quarter (22.6\%) started drinking before the permissible age limit of 18 years but the median age at first drink was 21 years(IQR:18-25 years) as seen in table 2 .

\section{Table 2: Pattern of alcohol use among the respondents}

\begin{tabular}{|c|c|}
\hline Variable & Freq. (\%) \\
\hline \multicolumn{2}{|l|}{ Alcohol use (n=323) } \\
\hline Current alcohol user & $219(67.8)$ \\
\hline Ex-alcohol user & $24(7.4)$ \\
\hline Never user & $80(24.8)$ \\
\hline \multicolumn{2}{|c|}{ Most recent drink $(n=219)$} \\
\hline Less than a week ago & $196(89.5)$ \\
\hline A week to a month ago & $14(6.4)$ \\
\hline More than a month ago & $9(4.1)$ \\
\hline \multicolumn{2}{|c|}{$\begin{array}{l}\text { Amount of alcohol consumed per week in } \\
\text { standard units }(n=219)\end{array}$} \\
\hline $1-50$ & $88(40.2)$ \\
\hline $51-100$ & $63(28.8)$ \\
\hline $101-150$ & $35(16.0)$ \\
\hline $151-200$ & $5(2.2)$ \\
\hline Above 200 & $28(12.8)$ \\
\hline $\begin{array}{l}\text { Median number of } \\
\text { alcohol units per week }\end{array}$ & $69.3(\mathrm{IQR}=23.1-138.6)$ \\
\hline \multicolumn{2}{|c|}{ Age at first drink (n-243)* } \\
\hline$<18$ years & $55(22.6)$ \\
\hline$>18$ years & $188(77.4)$ \\
\hline \multicolumn{2}{|l|}{ Level of drinking } \\
\hline Within reference limits & $24(11.0)$ \\
\hline Above reference limits & $195(89.0)$ \\
\hline \multicolumn{2}{|c|}{$\begin{array}{l}\text { *The minimum age allowable for alcohol } \\
\text { consumption in Nigeria is } 18 \text { years. }\end{array}$} \\
\hline $\begin{array}{l}\text { Up to } 20.7 \% \text { of the re } \\
\text { smokers and almost all o } \\
\text { most recent cigarette less } \\
\text { study. More than a third o } \\
\text { were heavy smokers }(>10 \\
\text { of smoking initiation rang } \\
\text { the median being } 22 \text { years, }\end{array}$ & $\begin{array}{l}\text { ondents were current } \\
\text { them }(92.5 \%) \text { had their } \\
\text { han a week prior to the } \\
\text { the respondents ( } 37.4 \%) \\
\text { sticks per day). The age } \\
\text { d from } 12-40 \text { years with } \\
\text { QR: } 18-22 \text { years) Almost }\end{array}$ \\
\hline
\end{tabular}


$18 \%$ started smoking before the permissible age limit of 18 years. As shown in table 3 .

Table 3: Pattern of cigarette use among the respondents

\begin{tabular}{lc}
\hline Variable & Freq.(\%) \\
\hline Cigarette use(n=323) & $67(20.8)$ \\
Current smoker & $24(7.4)$ \\
Ex smoker & $232(71.8)$ \\
Never-smoker & \\
Most recent cigarette (n=67) & $62(92.5)$ \\
Less than a week ago & $4(6.0)$ \\
A week to a month ago & $1(1.5)$ \\
Greater than a month & $25(37.3)$ \\
Number of cigarettes consumed per day(n=67) & $17(25.4)$ \\
1-4 sticks per day & $10(14.9)$ \\
5-9 sticks per day & $2(3.0)$ \\
10-14 sticks per day & $13(19.4)$ \\
15-19 sticks per day & \\
$>20$ sticks per sticks per day & $16(17.6)$ \\
Age at smoking initiation (n=91)* & $75(82.4)$ \\
$<18$ years & \\
$>18$ years & \\
*The minimum age allowable for & cigarette \\
consumption in Nigeria is 18 years &
\end{tabular}

Among respondents who had ever consumed alcohol or smoked cigarettes (75.2\%), 41.7\% of them started drinking before starting to smoke, while $40.5 \%$ of them started drinking and smoking at the same age. Only $17.8 \%$ started smoking before they started drinking. Up to $19 \%$ were dual users (i.e. both current drinkers and smokers) as at the time of the study.

Current drinking was associated with current smoking. Also, smokers consumed significantly more units of alcohol than nonsmokers. Neither age, marital status, education, religion nor duration of sex work was associated with either drinking status, smoking status or dual use as shown in table 4. A multivariate analysis was not carried out because only one variable was significant in the bivariate analysis (see figure 1).

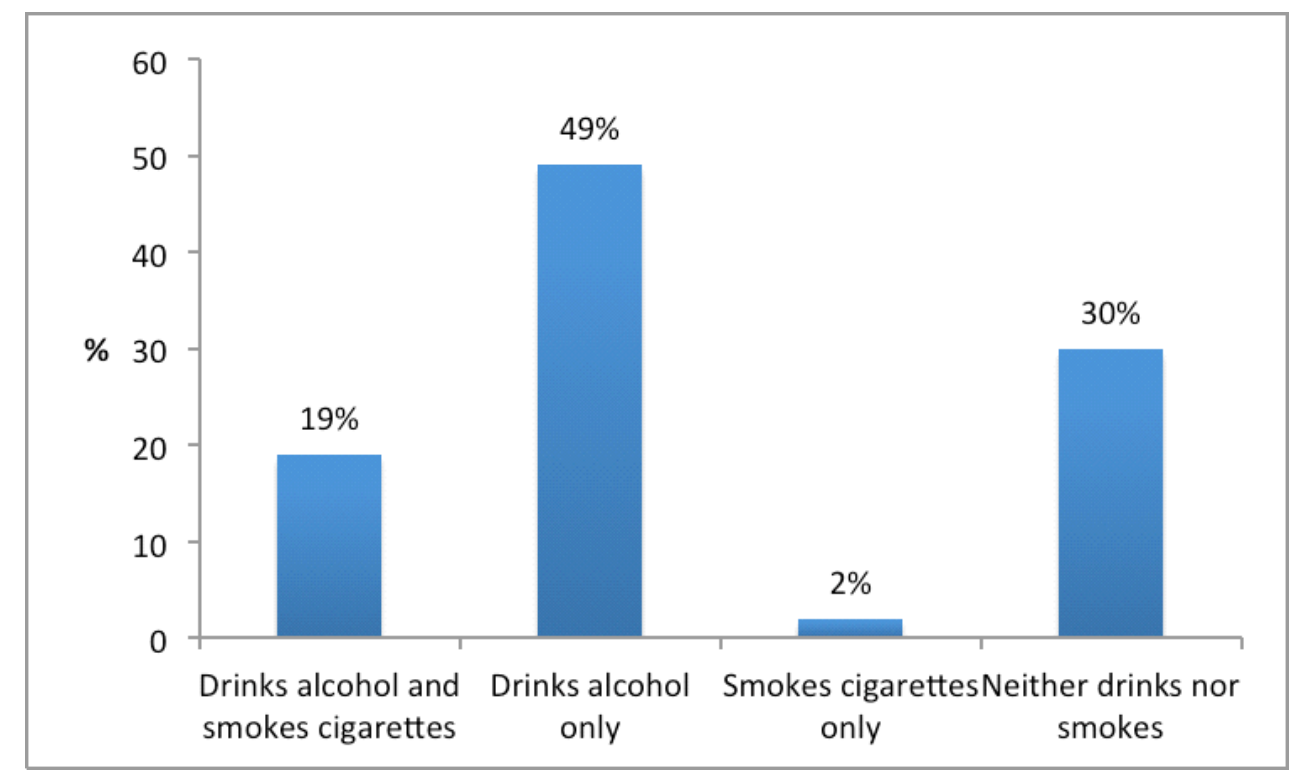

Figure 1: Pattern of alcohol, tobacco and dual use 
Table 4: Factors associated with current cigarette use

\begin{tabular}{|c|c|c|c|c|c|c|c|c|c|c|}
\hline Factor & $\begin{array}{l}\text { Current- } \\
\text { smoker } \\
\text { Freq.(\%) } n=67\end{array}$ & $\begin{array}{l}\text { Non- } \\
\text { smoker } \\
\text { Freq.(\%) } \\
n=256\end{array}$ & $\mathbf{P}$ & $\begin{array}{l}\text { Current } \\
\text { drinker } \\
\text { Freq.(\%) } \\
n=219\end{array}$ & $\begin{array}{l}\text { Non- } \\
\text { drinker } \\
\text { Freq.(\%) } \\
\text { n=104 }\end{array}$ & $\mathbf{P}$ & $\begin{array}{l}\text { Dual } \\
\text { user }^{\#} \\
\text { Freq.(\%) } \\
\mathrm{n}=61\end{array}$ & $\begin{array}{l}\text { Not dual } \\
\text { user } \\
\text { Freq.(\%) } \\
n=262\end{array}$ & $\mathrm{p}$ & $\begin{array}{l}\text { Total } \\
\text { Freq.(\%) } \\
\mathrm{N}=323\end{array}$ \\
\hline \multicolumn{11}{|l|}{ Age group (years) } \\
\hline $15-24$ & $23(21.3)$ & $85(78.7)$ & 0.631 & $73(67.6)$ & $35(32.4)$ & 0.247 & $21(19.4)$ & $87(80.6)$ & 0.392 & 108(100) \\
\hline $25-34$ & $35(22.0)$ & $124(78.0)$ & & $113(71.1)$ & $46(28.9)$ & & $33(20.8)$ & $126(79.2)$ & & 159100) \\
\hline 35 and above & $9(16.1)$ & $47(83.9)$ & & $33(58.9)$ & $23(41.1)$ & & $7(12.5)$ & $45(87.5)$ & & $56(100)$ \\
\hline \multicolumn{11}{|l|}{ Marital status } \\
\hline Married & $3(18.8)$ & $13(81.2)$ & 0.928 & $10(65.5)$ & $6(37.5)$ & 0.223 & $3(18.8)$ & $13(81.3)$ & 0.999 & $16(100)$ \\
\hline Separated/Divorced/Widowed & $23(21.9)$ & $82(78.1)$ & & $65(61.9)$ & $40(38.1)$ & & $20(19.0)$ & $85(81.0)$ & & 105(100) \\
\hline Single & $41(20.1)$ & 161(79.9) & & $144(71.3)$ & $58(28.7)$ & & $38(18.8)$ & $164(81.2)$ & & $202(100)$ \\
\hline \multicolumn{11}{|l|}{ Level of education } \\
\hline No formal education & $5(20.0)$ & $20(80.0)$ & 0.968 & $14(56.0)$ & $11(44.0)$ & 0.299 & $5(20.0)$ & $20(80.0)$ & 0.988 & $25(100)$ \\
\hline Completed primary & $40(20.4)$ & $156(79.6)$ & & $138(70.4)$ & $58(29.6)$ & & $37(18.9)$ & $159(81.1)$ & & 196(100) \\
\hline Completed secondary and above & $22(21.6)$ & $80(78.4)$ & & $67(65.7)$ & $35(34.3)$ & & $19(18.6)$ & $83(81.4)$ & & $102(100)$ \\
\hline \multicolumn{11}{|l|}{ Religion } \\
\hline Christianity & 61(19.9) & $246(80.1)$ & & $210(68.4)$ & $97(31.6)$ & 0.310 & $56(18.2)$ & $251(81.8))$ & 0.195 & $307(100)$ \\
\hline Islam & $6(37.5)$ & $10(62.5)$ & $0.111 !$ & $9(56.3)$ & $7(43.8)$ & & $5(31.3)$ & $11(68.8)$ & & $16(100)$ \\
\hline \multicolumn{11}{|l|}{ Duration of sex work } \\
\hline Less than six months & $15(18.8)$ & $65(81.2)$ & 0.834 & $57(71.3)$ & $23(28.8)$ & 0.748 & $15(18.8)$ & $65(81.3)$ & 0.999 & $80(100)$ \\
\hline Six-twelve months & $17(20.2)$ & $67(79.8)$ & & $56(66.7)$ & $28(33.3)$ & & $16(19.0)$ & $68(81.0)$ & & $84(100)$ \\
\hline Above one year & $35(22.0)$ & $124(78.0)$ & & $106(66.7)$ & $53(33.3)$ & & $30(18.9)$ & $129(81.1)$ & & $159(100)$ \\
\hline \multicolumn{11}{|l|}{ Drinking status } \\
\hline Current drinker & $61(27.9)$ & $158(72.1)$ & $<0.001 *$ & & & & & & & $219(100)$ \\
\hline Not current drinker & $6(5.8)$ & $98(94.2)$ & & & & & & & & 104(100) \\
\hline Mean units of alcohol / week & $110.39 \pm 109.8$ & $83.79 \pm 72.7$ & $0.038^{*}$ & & & & $\begin{array}{l}110.40 \pm 10 \\
9.83\end{array}$ & $\begin{array}{l}86.70 \pm \\
77.16\end{array}$ & 0.071 & $91.2 \pm 85.2$ \\
\hline $\begin{array}{l}\text { Mean number of cigarettes per } \\
\text { week } n=67\end{array}$ & & & & $8.31 \pm 6.7$ & $7.0 \pm 6.5$ & 0.648 & $8.31 \pm 6.7$ & $7.00 \pm 6.48$ & 0.647 & $8.19 \pm 6.2$ \\
\hline Age at first drink & $20.9 \pm 5.6$ & $22.5 \pm 6.3$ & 0.071 & & & & $20.9 \pm 5.69$ & $22.58 \pm 6.2$ & 0.065 & $22.15 \pm 6.1$ \\
\hline Age at first cigarette & & & & $22.87 \pm 5.9$ & $24.57 \pm 7.5$ & 0.343 & $22.7 \pm 5.8$ & $24.1 \pm 6.9$ & 0.294 & $23.13 \pm 6.1$ \\
\hline
\end{tabular}

\#-Dual user is both a current drinker and smoker

*Statistically significant

!:Fisher's exact $\mathrm{p}$ value

\section{Discussion}

The prevalence of current alcohol use (67.8\%) among this group of women clearly exceeds estimates from studies conducted among other groups of Nigerian women. For example, the results were much higher than the figures reported in a study in five states in Nigeria and the federal capital territory where $22 \%$ of women identified themselves as current drinkers. ${ }^{31}$ Relatively higher rates of alcohol use have also been reported among FSW's in other settings. A systematic review of alcohol drinking patterns among female sex workers reported a range of $73.3 \%$ to $74.8 \%$ as current drinkers. ${ }^{32}$

The fact that almost all $(89.0 \%)$ of the women in this study consumed more than the reference limits for alcohol intake for females is an indication that health risks other than sexually transmitted diseases (STI's) should be considered in this population. Our figures were much higher than those reported in a large community based study carried out among men and women in the western part of Nigeria where only $0.5 \%$ of respondents reported alcohol abuse. ${ }^{33}$ The median amount of alcohol consumed per week in this study was 69.3 units. Our findings are in keeping with similar studies in Nigeria which report that Nigerian women who consumed alcohol were often frequent or heavy drinkers. ${ }^{19,31}$ For the women in this study, exceeding the reference limits clearly put them at an increased risk of both the short and long term consequences of harmful alcohol intake. This should be a cause of concern to program planners and policy makers.

The prevalence of cigarette smoking among the study population, though much lower than alcohol use, was still considerably higher than the national average. The prevalence of smoking among the women in this study (20.8\%) was almost 200 times 
the figures reported for women $(0.2 \%)$ and almost double the values reported for men (9\%) in the 2008 NDHS. ${ }^{19}$ One other issue of concern is the frequency and amount of cigarettes smoked by these women. More than a third of them (37.3\%) smoked heavily ( $>10$ sticks per day) putting them at increased risk for the many health effects of smoking. Comparatively, only $17 \%$ of men in the 2008 NDHS were heavy smokers. ${ }^{19}$

Almost one in five respondents was a dual user (i.e. current drinker and smoker). The health effects of smoking combined with alcohol use may be more severe among these dual users. ${ }^{12}$ These values are higher than those observed in a similar study among Cuban women where only $4 \%$ were dual users. ${ }^{34}$

This is probably because the Cuban study was carried out in the general population as compared with this study carried out among sex workers. As with studies done in other populations, ${ }^{35-37}$ Smoking was associated with alcohol consumption in this study. Smokers also drank significantly more units of alcohol per week than non-smokers. The age at drinking initiation also tended to be lower among current smokers when compared to non-smokers. Programs that combine alcohol and tobacco dependence treatment may be beneficial for this group of women.

\section{Limitations}

This study is one of the few studies that document the pattern of alcohol and tobacco use among commercial sex workers in Nigeria. It however has some limitations. The predictors of alcohol or tobacco use among these women could not be determined using a logistic regression model, as the significant variables on the bivariate analysis were low. Another limitation is the possibility of recall bias, which may be due to inaccurate recollection of the number of cigarettes consumed per day or the amount of alcohol consumed in the preceeding week. It nevertheless provides some evidence for the establishment of new programs or incorporation of alcohol and tobacco control into existing programs for female sex workers.

\section{Conclusion}

The prevalence of harmful alcohol use and cigarette smoking are very high among this group of female sex workers. Programs that address the use of these substances should be made available for these women.

African Health Sciences Vol 13 Issue 2 June 2013

\section{References}

1. World Health Organization. Global status report on non-communicable diseases 2010 . Available at www.who.int/nmh/publications/ ncd_report_full_en.pdf. Accessed August 2012.

2. World Health Organization. From burden to best buys: Reducing the impact of non-communicable diseases in low and middle-income countries. Available at www.who.int/n m h/publications / best_buys_summary.pdf. Accessed August 2012.

3. World Health Organization. Global health risks, 2004. Available at www.who.int/healthinfo/ global.../GlobalHealthRisks_report_full.pdf. Accessed August 2012.

4. Bobo JK, Husten C. Socio-cultural influences on smoking and drinking. Alcohol Research \& Health 2000;24(4):225-232.

5. Grant BF, Hasin DS, Chou SP Stinson FS, and Dawson DA. Nicotine dependence and psychiatric disorders in the United States: Results from the National Epidemiologic Survey on Alcohol and Related Conditions. Archives of General Psychiatry 2004; 61:1107-1115.

6. National Institute of Alcohol Abuse and Alcoholism. Alcohol Alert: Alcohol and tobacco. January 2007 vol. 71 . Available at http:/ /pubs.niaaa.nih.gov/publications/AA71/ AA71.htm. Accessed August 2012

7. U.S. Department of Health and Human Services. The health consequences of smoking: a report of the surgeon general. Atlanta, Georgia: U.S. Department of Health and Human Services, Centers for Disease Control and Prevention, National Center for Chronic Disease Prevention and Health Promotion, Office on Smoking and Health; 2004:1-23.

8. Franceschi S, $\mathrm{T}$

R, Barra S, Baron AE, Negri E, Bidoli E et al. Smoking and drinking in relation to cancers of the oral cavity, pharynx, larynx, and esophagus in Northern Italy. Cancer Research 1990;50:65026507.

9. Zheng TZ, Boycle P, Hu HF, Duan J, Jian PJ, Ma DQ et al. Tobacco smoking, alcohol consumption, and risk of oral cancer: A casecontrol study in Beijing, People's Republic of China. Cancer Causes and Control 1990;1:173-179. 
10. Negri E, La Vecchia C, Franceschi S and Tavani A. Attributable risk for oral cancer in Northern Italy. Cancer Epidemiology Biomarkers and Prevention 1993;2:189-193.

11. Campaign for tobacco free kids. Fact sheet on women and smoking. Available at http:// www.tobaccofreekids.org/research / factsheets/pdf/0004.pdf Accessed August 2012.

12. United States Centre for Disease Control. Fact sheet: Excessive alcohol use and women's health. 2010. Available at http://www.cdc.gov/ alcohol/fact-sheets/womens-health.htm Accessed August 2012

13. Ashley MJ, Olin JS, Le Riche WH, Kornaczewski A, Schmidt W and Rankin JG. Morbidity in alcoholics. Evidence for accelerated development of physical disease in women. Archives of Internal Medicine 1977;137(7):883-887

14. National Institute of Alcohol Abuse and Alcoholism. Alcohol, a women's health issue. 2008. Available at http://pubs.niaaa.nih.gov/ publications/brochurewomen/women.htm. Accessed August 2012.

15. Loft S, Olesen KL, Dossing M. Increased susceptibility to liver disease in relation to alcohol consumption in women. Scandinavian Journal Gastroenterology 1987;22(10):1251-1256.

16. Iyasu S, Randall LL, Welty TK Hsia J, Kinney HC, Mandell F et al. Risk factors for sudden infant death syndrome among northern plains Indians. Journal of the American Medical Association 2002;288(21):2717-2723.

17. Kesmodel U, Wisborg K, Olsen SF, Henriksen TB and Sechler NJ. Moderate alcohol intake in pregnancy and the risk of spontaneous abortion. Alcohol and Alcoholism 2002;37(1):8792.

18. World Health Organization. Global status report on Alcohol Nigeria country profile 2004. Available http://www.who.int/ substance_abuse/publications/en/nigeria.pdf. Accessed August 2012.

19. National Population Commission, Federal Republic of Nigeria. Nigeria demographic and health survey. November 2009. Available at: http://www.measuredhs.com/pubs/pdf/ FR222/FR222.pdf. Accessed January 2010

20. Plant ML, Plant MA, Peck DF, Setters J. The sex industry, alcohol and illicit drugs: implications for the spread of HIV infection. British Journal of Addiction 1989;84:53-9

21. UNAIDS. Sex work and HIV/AIDS: UNAIDS technical update. Geneva, Switzerland: The Joint United Nations Programme on HIV/AIDS (UNAIDS); 2002. http://data.unaids.org/Publications/IRCpub02/JC705-SexWork-TU_en.pdf Available at Accessed 28 March 2009

22. Aral SO, St Lawrence JS, Tikhonova L, Safarova E, Parker KA, Shakarishvili A. The social organization of commercial sex work in Moscow, Russia. Sexually Transmitted Diseases 2003;30:39-45

23. Choi SY, Chen KL, Jiang ZQ. Clientperpetuated violence and condom failure among female sex workers in southwestern China. Sexually Transmitted Diseases 2008;35:1416

24. De Graaf R, Vanwesenbeeck I, van Zessen G, Straver CJ, Visser JH. Alcohol and drug use in heterosexual and homosexual prostitution, and its relation to protection behaviour. AIDS Care 1995;7:35-47

25. Kalichman SC, Simbayi LC, Kaufman M, Cain $\mathrm{D}$, Jooste $\mathrm{S}$. Alcohol use and sexual risks for HIV/AIDS in sub-Saharan Africa: systematic review of empirical findings. Prevention Science 2007 Jun;8(2):141-51

26. Baker LM, Case P, Policicchio DL. General health problems of inner-city sex workers: A pilot study. Journal of the Medical Library Association 2003;91:67-71

27. Freight for transport development. HIV/AIDS prevention project along the Abidjan- Lagos transport corridor.2010. Available at http:// www.ppiaf.org/freighttoolkit/sites/default/ files/casestudies/HIV-AIDS.pdf. Accessed September 2012

28. Finch K, Novotny TE, Ma S, Qin D, Xia W, Xin G. Smoking knowledge, attitudes, and behaviors among rural-to-urban migrant women in Beijing, China. Asia Pacific Journal of Public Health. 2010 Jul;22(3):342-53.

29. National Health Service. What is a unit of alcohol? Available at http://www.nhs.uk/ Livewell/alcohol/Pages/alcohol-units.aspx. Accessed May 2012.

30. International Centre for Alcohol Policies. International drinking 
31. Guidelines, 2003. Available at http://

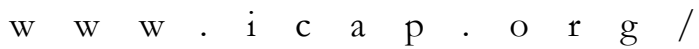
LinkClick.aspx?fileticket $=\mathrm{KtXj8P}$

GibT8\%3D\&tabid=75. Accessed September 2012.

32. World Health Organization. Alcohol, gender and drinking problems, perspectives from low and middle-income countries. World Health Organization. Geneva 2005.

33. Scorgie F, Chersich MF, Ntaganira I, Gerbase A, Lule F and Lo YR. Socio-demographic characteristics and behavioral risk factors of female sex workers in Sub-Saharan Africa: a systematic review. AIDS Behaviour 2012 May;16(4):920-33.

34. Gureje O, Lasebikan VO and Kola L. Lifetime and 12-month prevalence of mental disorders in the Nigerian Survey of Mental Health and
Well-Being. British journal of Psychiatry 2006;188:465-471.

35. Varona P, Chang M, García RG and Bonet M. Tobacco and alcohol use in Cuban women. MEDICC Rev. 2011 Oct;13(4):38-44.

36. United States centre for disease control. Excessive alcohol use and risks to women's health. Available at http://www.cdc.gov/ alcohol/fact-sheets/womens-health.htm. Accessed in August 2012.

37. Leatherdale ST, Burkhalter R. The substance use profile of Canadian youth: exploring the prevalence of alcohol, drug and tobacco use by gender and grade. Addictive Behaviours 2012 Mar;37(3):318-22.

38. Kirby T, Barry AE. The substance use profile of Canadian youth: exploring the prevalence of alcohol, drug and tobacco use by gender and grade. Journal of School Health 2012 Aug;82(8):371-9. 